\title{
Sensitivity Study of the RegCM4's Surface Schemes in the Simulations of West Africa Climate
}

\author{
Adjon Anderson Kouassi ${ }^{*}$, Brahima Kone², Siélé Silue ${ }^{3}$, Alima Dajuma ${ }^{3}$, \\ Toure E. N'datchoh², Marcellin Adon', Arona Diedhiou ${ }^{2,4}$, Véronique Yoboue ${ }^{2}$
}

${ }^{1}$ Laboratoire des Sciences et Technologie de l'Environnement (LSTE), Université Jean Lorougnon Guédé, Daloa, Côte d'Ivoire ${ }^{2}$ Laboratoire des Sciences de la Matière, de l'Environnement et de l'Energie Solaire (LASMES), Université Félix Houphouët-Boigny, Abidjan, Côte d'Ivoire ${ }^{3}$ Université Péléforo Gon Coulibaly, Korhogo, Côte d'Ivoire ${ }^{4}$ Université Grenoble Alpes, IRD, CNRS, Grenoble INP, IGE, Grenoble, France

Email: *adjonkouassi@gmail.com

How to cite this paper: Kouassi, A.A., Kone, B., Silue, S., Dajuma, A., N'datchoh, T.E., Adon, M., Diedhiou, A. and Yoboue, V. (2022) Sensitivity Study of the RegCM4's Surface Schemes in the Simulations of West Africa Climate. Atmospheric and Climate Sciences, 12, 86-104. https://doi.org/10.4236/acs.2022.121007

Received: Ausgust 9, 2021

Accepted: September 16, 2021

Published: January 4, 2022

Copyright (อ 2022 by author(s) and Scientific Research Publishing Inc. This work is licensed under the Creative Commons Attribution International License (CC BY 4.0).

http://creativecommons.org/licenses/by/4.0/

\section{(c) (i) Open Access}

\begin{abstract}
Two simulations of five years (2003-2007) were conducted with the Regional Climate models RegCM4, one coupled with Land surface models BATS and the other with CLM4.5 over West Africa, where simulated air temperature and precipitation were analyzed. The purpose of this study is to assess the performance of RegCM4 coupled with the new CLM4.5 Land surface scheme and the standard one named BATS in order to find the best configuration of RegCM4 over West African. This study could improve our understanding of the sensitivity of land surface model in West Africa climate simulation, and provide relevant information to RegCM4 users. The results show fairly realistic restitution of West Africa's climatology and indicate correlations of 0.60 to 0.82 between the simulated fields (BATS and CLM4.5) for precipitation. The substitution of BATS surface scheme by CLM4.5 in the model configuration, leads mainly to an improvement of precipitation over the Atlantic Ocean, however, the impact is not sufficiently noticeable over the continent. While the CLM4.5 experiment restores the seasonal cycles and spatial distribution, the biases increase for precipitation and temperature. Positive biases already existing with BATS are amplified over some sub-regions. This study concludes that temporal localization (seasonal effect), spatial distribution (grid points) and magnitude of precipitation and temperature (bias) are not simultaneously improved by CLM4.5. The introduction of the new land surface scheme CLM4.5, therefore, leads to a performance of the same order as that of BATS, albeit with a more detailed formulation.
\end{abstract}




\section{Keywords}

Regional Climate Model, Land Surface Scheme, West Africa Climate, RegCM, Precipitation, West African Monsoon, Simulated Data

\section{Introduction}

The complexity and diversity of the dynamic and physical processes of the West African Monsoon (WAM) make its simulation a challenge for climate models. Realistic climate reproduction requires accurate simulation. The most suitable tools to capture the characteristics of WAM are Regional Climate Models (RCM) [1] [2] [3]. Thus, optimizing RCMs configurations will allow for accurate climate simulations. To achieve this, several studies have been conducted, either by improving the current schemes in determining the best combination of existing physics schemes to use for a certain region, or implementing new physical parameterization schemes [4] [5] [6] [7] [8]. The performance of the models varies according to the region, season and physical configurations. In West Africa, many studies have attempted to improve the simulation of precipitation during the summer season, based on the sensitivity of the models to cumulus convection schemes [9]. Although the accurate simulation of precipitation is directly related to cumulus convection scheme and its interaction with other physical processes, the choice of land surface scheme can also contribute to improving the performance of models in simulating climate over West Africa. Chen et al. [10] demonstrated over eastern China, that the CLM3.5 surface scheme significantly improves precipitation and temperature simulations with respect to the NOAH land surface scheme when coupled with Weather Research and Forecasting (WRF). Steiner et al. [11] also showed the role of the land surface scheme in improving land-atmosphere moisture, energy exchange and associated surface climate feedback by replacing the standard BATS surface scheme with CLM in RegCM. Nevertheless, Halder et al. [12] demonstrated that the use of CLM can lead to poorer performance of RegCM than BATS over India. The new RegCM version 4 has been improved with substantial development of the software code and physical representations [2] and the introduction of CLM4.5 as a new option for describing land surface processes. Several studies have shown that the choice of a land surface scheme has a substantial impact on climate model simulation [13]. Thus, the performance of RegCM4 coupled with the new CLM4.5 surface scheme needs to be investigated together with the standard BATS scheme to find the best configuration of RegCM4 for the West African, and provide relevant information to RegCM4 users.

In addition, this study could improve our understanding of the sensitivity of surface schemes in West Africa climate simulation. It will also contribute to estimating the advantages and disadvantages of the RegCM4 model by coupling it with the BATS and CLM4.5 land surface schemes over West Africa. This paper is structured as follows: Model, data and numerical experiments used to investigate 
the RegCM4 performance are described in Section 2. Section 3 assesses the performance of the RegCM4 model, through the BATS and CLM surface schemes, over West Africa. The analysis will focus on precipitation and temperature, a statistical analysis will be conducted to better highlight the model's performance. The main conclusions are summarized in Section 4.

\section{Models and Methodology}

\subsection{Model Description}

The regional climate model, used in this study is named RegCM4. It is a limited area model, with finite-difference discretization using a terrain-following $\sigma$ (sigma) pressure vertical coordinate system and an Arakawa B-grid finite differencing algorithm [2]. RegCM4 was developed at ICTP and aimed to study mesoscale processes in the atmosphere over a selected area of the Earth.

The release used in this study is RegCM4.7. The non-hydrostatic dynamical core of the mesoscale model version 5 (MM5) [14] has been ported to RegCM4 while maintaining the existing hydrostatic core. We used in this study the non-hydrostatic core of RegCM4. The radiation scheme is derived from the NCAR Community climate Model 3 (CCM3) described in Kiehl et al. [15], and includes a representation of aerosols following Zakey et al. [16]. It also includes many complex detailed processes such as, radiative transfer processes, grid-scale and subgrid-scale cloud processes, turbulence mixing processes and land-surface processes [2]. RegCM4 model shows an improvement performance compared to elder version especially in the formulation of surface scheme.

\subsection{Land Surface Scheme}

BATS has been described in detail by Dickinson et al. [17], it's the standard land surface scheme used with RegCM, since many years. This scheme has been improved over years through different versions. It includes a vegetation layer, a snow layer and a 3-layer soil scheme. The land cover descriptions consist of 20 surface types, 12 soil colors, and various soil textures, according to the FAO Soil Map of the World [18]. A mosaic-type parameterization of the sub grid-scale topography and land use was implemented. The parameterization used a regular fine scale surface sub grid for each coarse-model grid cell. The representation of the surface hydrology of the model includes predictive equations for the water content of the soil surface layer and the root zone. These equations take into account precipitation, snow, transpiration, surface runoff, infiltration below the root zone and diffuse water exchange between soil layers. The water balance is calculated with a 1 to $2 \mathrm{~m}$ deep, which is the most important layer of soil for the biological process. This scheme showed a remarkable improvement of the surface hydrological cycle simulation in mountainous regions [19].

CLM4.5 uses a set of parameters, coupling biogeophysical, biogeochemical and biogeographic processes to describe the exchange of energy, momentum, water and carbon between the surface and the atmosphere. The Grid cells are di- 
vided into a first subgrid hierarchy composed of multiple land units (wetlands, vegetation, lakes, and urban) and second and third subgrid hierarchies for vegetated land units, including different snow/soil columns and plant functional types [20]. The percentage of sand and clay varied with depth based on the 5-minute resolution IGBP soil dataset to develop a soil texture datasets [21]. Biogeophysical processes are calculated for each land unit, column, and then averaged before returning to the atmospheric model. Soil temperature and water content are calculated with a multiple layer model. The soil column is discretized into ten layers, where the minimum and maximum depths of the soil layer are $0.71 \mathrm{~cm}$ and $2.86 \mathrm{~m}$, respectively. CLM4.5 was updated by integrating Moderate Resolution Imaging Spectroradiometer (MODIS) products improving the canopy integration and interception schemes [22] [23].

As described in detail by Oleson et al. [20], CLM4.5 is a more advanced package compared to BATS. A brief comparison of the parameters of the BATS and CLM4.5 land surface schemes is presented in Table 1.

\subsection{Methodology}

The RegCM4 model is used in this study with the two available land-surface schemes (BATS and CLM4.5). Two simulations that are identical in all respects, except for the land surface scheme, have been launched for West Africa. The first simulation uses the BATS scheme [17] while the second uses the CLM 4.5 scheme [21].

Table 2 shows general design of the simulations, performed to investigate the sensivity of RegCM's surface scheme over west Africa. The simulation domain in this study spanned from longitude $20 \mathrm{~W}$ to $20 \mathrm{E}$ and latitude $05 \mathrm{~S}$ to $21 \mathrm{~N}$. The horizontal grid resolution is $25 \times 25 \mathrm{~km}$ about $0.23^{\circ} \times 0.23^{\circ}$ (Figure 1). We have 174 grid points (lon.) and 114 (lat.) and the vertical grids are composed of 18 sigma $(\sigma)$ levels stretching from near the surface to the model top $(10 \mathrm{hPa})$. The simulations are initialized and forced every six hours, by the ERA-Interim reanalysis [24] with a grid spacing of $1.5^{\circ} \times 1.5^{\circ}$. Sea-air temperatures (SSTs) were

Table 1. Comparison of BATS and CLM4.5 land-surface schemes configuration in RegCM4 Model.

\begin{tabular}{ccc}
\hline & BATS & CLM4.5 \\
\hline $\begin{array}{c}\text { Number of soil layers } \\
\text { Soil temperature calculation }\end{array}$ & 3 & 10 \\
Soil freezing and thawing & Force-restore method & $\begin{array}{c}\text { Head diffusion equation } \\
\text { A new frozen soil model } \\
\text { (supercooled soil water) }\end{array}$ \\
Number of snow layers & Yes & 5 \\
Land use parameters & 1 & $\begin{array}{c}\text { landunits, } 17 \text { types (PFTs) } \\
\text { represent vegetation } \\
\text { Surface datasets }\end{array}$ \\
Soil texture & FAO soil map of the world & MODIS products \\
\hline
\end{tabular}


Table 2. General design of the RegCM simulations over west Africa.

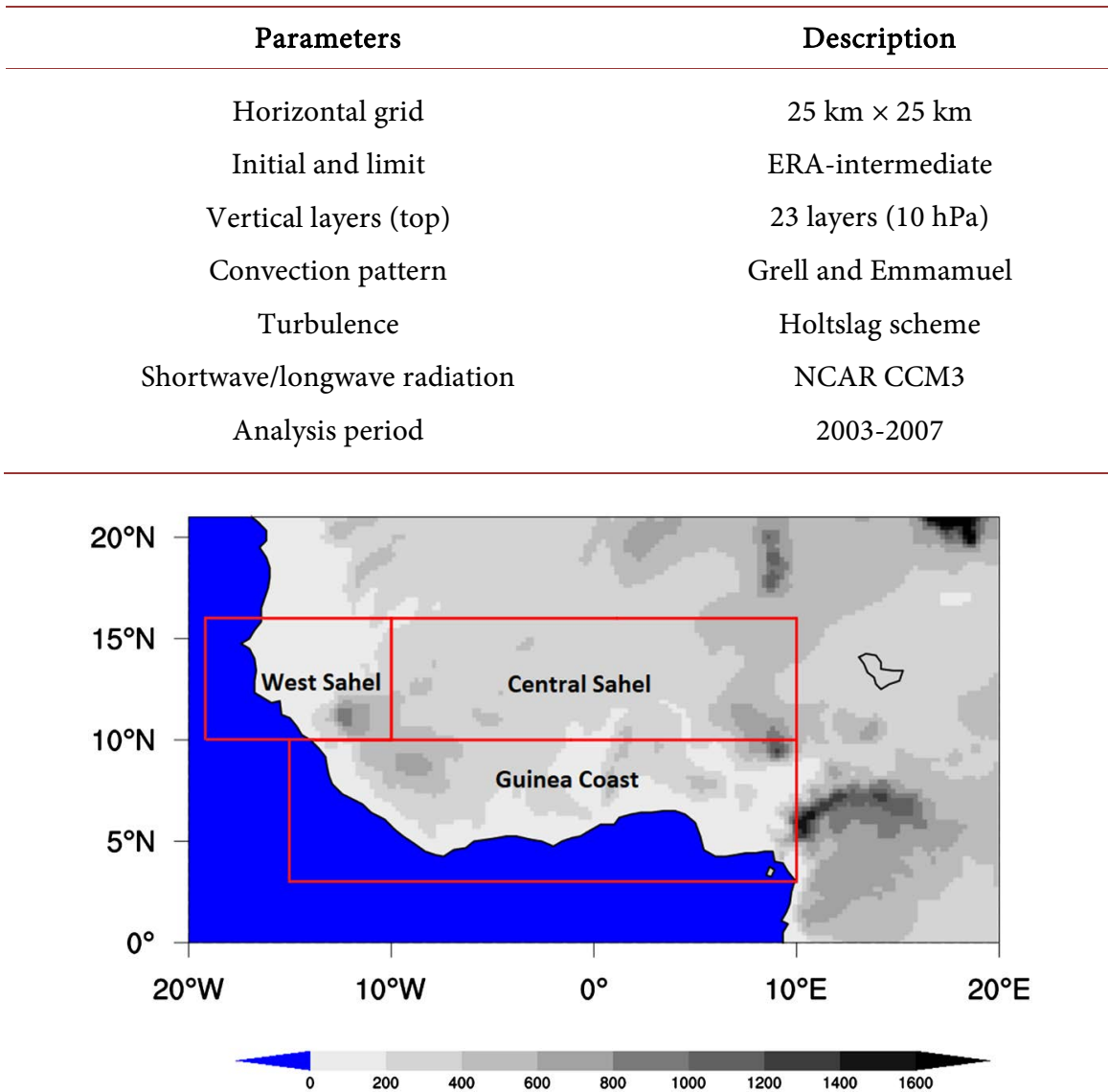

Figure 1. Topography $(\mathrm{m})$ of simulation domain, with the entire West African domain and three sub regions marked with boxes: Guinea coast (GCO), Central Sahel (CSA) and West Sahel (WSA).

acquired from NOAA optimal interpolation weekly SST data resolution. In order to maintain the model computational stability, an integration time step of 60 seconds was used. Each simulation (BATS or CLM) starts from 01 October 2002 to 31 December 2007. The results from the first 03 months were discarded as the model spin up. Three observational datasets were considered in this study: 1) The Tropical Precipitation Measuring Mission 3B43V7 (TRMM) [25] available from 1998 to 2013 with resolution $\left.0.5^{\circ} \times 0.5^{\circ} .2\right)$ The new quasi-global $\left(50^{\circ} \mathrm{S}\right.$ $50^{\circ} \mathrm{N}$ ) daily precipitation of Climate Hazards Group InfraRed Precipitation with Station dataset (CHIRPS) [26] with high resolution $\left(0.05^{\circ}\right)$. 3) The Climate Prediction Center (CPC) merged analysis, which is developed by the Climate Diagnostic Center (US Dept of Commerce) following the methodology of Xie and Arkin [27] with $0.5 \times 0.5$ latitude-longitude resolution for the period from 1948 to the present. We referred to bilinear interpolation method to facilitate the comparison with RegCM4 simulations [28]. Our study includes a statistical analysis based on statistics quantitative:

1) Mean Bias (MB) which is the difference between the area-averaged value of the simulation and the observation. 2) Spatial Root Mean Square difference 
(RMSD) and 3) the spatial correlation called pattern correlation coefficient (PCC). The RMSD and PCC provide information at the grid-point level, while the MB does so at the regional level. The Taylor diagram [29] is used to summarize the assessments above and to show the deviation of different model configuration results from observations.

The model sensivity is also examined in four sub-regions (Figure 1) according to [9]. Each sub regions presents different characteristics of precipitation annual cycle: Central Sahel $\left(10^{\circ} \mathrm{W}-10^{\circ} \mathrm{E} ; 10^{\circ} \mathrm{W}-16^{\circ} \mathrm{N}\right)$, West Sahel $\left(18^{\circ} \mathrm{W}-10^{\circ} \mathrm{W}\right.$; $\left.10^{\circ} \mathrm{W}-16^{\circ} \mathrm{N}\right)$, Guinea Coast $\left(15^{\circ} \mathrm{W}-10^{\circ} \mathrm{E} ; 3^{\circ} \mathrm{W}-10^{\circ} \mathrm{N}\right)$ and West Africa $\left(20^{\circ} \mathrm{W}\right.$ $\left.-20^{\circ} \mathrm{E} ; 5^{\circ} \mathrm{S}-21^{\circ} \mathrm{N}\right)$. Our analysis focuses on the precipitation and the $2 \mathrm{~m}$ air temperature in the summer of June to September (JJAS) over West Africa.

\section{Results and Discussion}

\subsection{Temperature}

\subsubsection{Spatial Distribution}

Figure 2 shows the spatial distribution of daily air temperature, averaged over the period 2003-2007, for the observational data CPC (Figure 2(a)) and model simulations using BATS and CLM4.5 Figure 2(b) and Figure 2(c), respectively.

The observation data CPC present a zonal distribution of $2 \mathrm{~m}$ air temperatures over West Africa Figure 2(a). The minimun values of air temperatures about $22.5^{\circ} \mathrm{C}$, are located over mountain areas such as guinea highlands, Jos Plateau in Nigeria and Cameroon mountains. However, the maximum values of air temperatures about $42.5^{\circ} \mathrm{C}$ over the Sahara.

The both model simulations (Figure 2(b) and Figure 2(c)) well capture the spatial extend of the maximum and minimum air temperatures, including the south-north temperature gradient. This gradient is a determining factor in the evolution of the East African Jet (AEJ) [30]. The minimum and maximum air temperatures simulated by BATS configuration are $20^{\circ} \mathrm{C}$ and $52.5^{\circ} \mathrm{C}$ against $20^{\circ} \mathrm{C}$ to $60^{\circ} \mathrm{C}$ for CLM 4.5 configuration.

Figure 3 shows the biases between the model simulations (BATS, CLM) and observtion dataset (CPC) air temperature. Biases are expressed in percentage of relative error (Figures 3(a)-(c)). BATS simulation show a dominant of bias
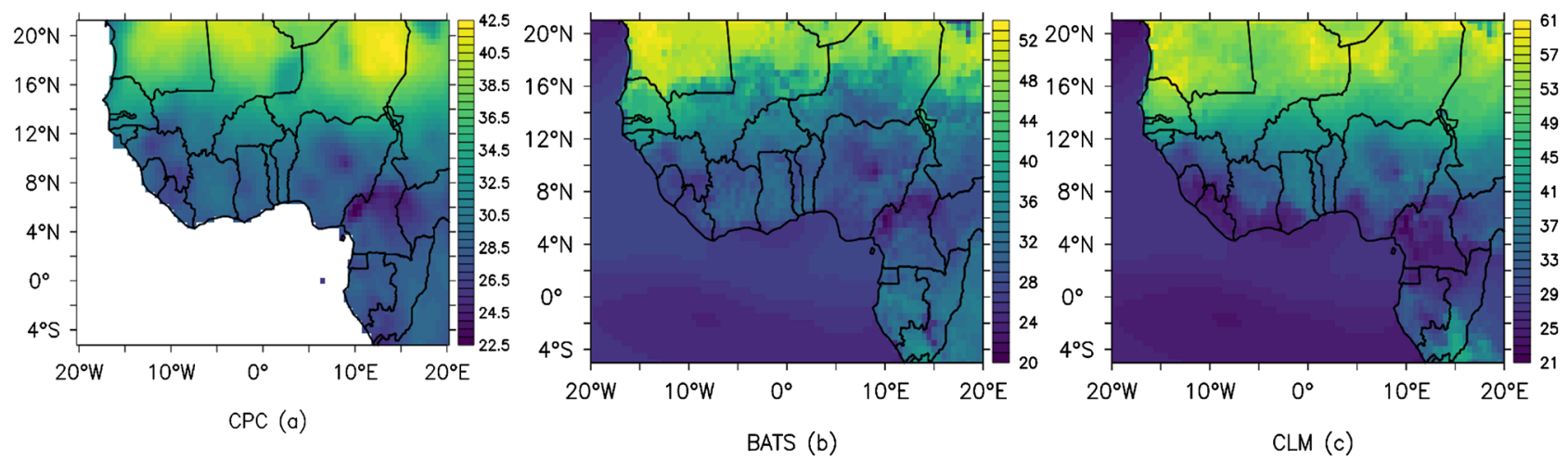

Figure 2. Spatial distribution of 2 meter ir temperature $\left({ }^{\circ} \mathrm{C}\right)$ from JJAS (2003-2004) over West Africa. CPC (a), BATS (b), CLM (c). 

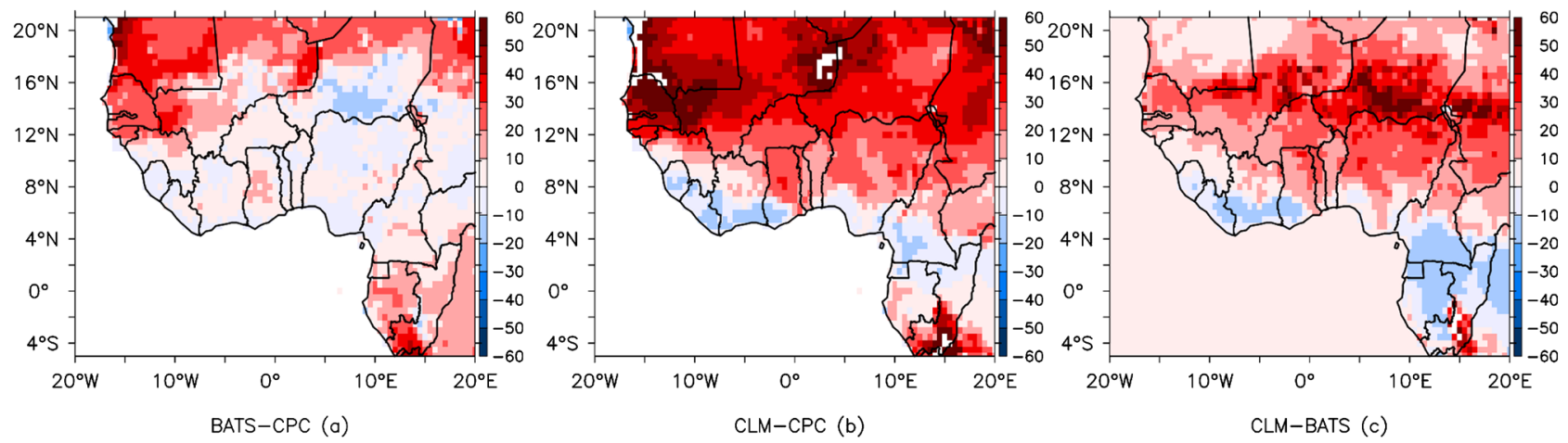

Figure 3. $2 \mathrm{~m}$ Air temperature bias $\left({ }^{\circ} \mathrm{C}\right) \mathrm{JJAS}$ over West Africa from observations (CPC) and simulations (BATS and CLM).

about $\pm 10 \%$ over most of guinea coast and sahel zones. While CLM4.5 configuration presents a negative bias of $20 \%$, along the coastline from Sierra leone to Ghana and Cameroon, Figure 3(c) with a positive biase over Sahel and Sahara zones more than $20 \%$. However, it is very difficult to determine the origins of RCM biases, because they involve changes in surface-atmosphere interactions and are dependent on many factors such as surface albedo, cloudiness, temperature convection and surface water and energy fluxes [31].

\subsubsection{Annual Cycle}

Figure 4 shows the annual cycle of air temperature over different sub regions of West Africa: Central Sahel, West Sahel, Guinea Coast, West Africa, analysis are based of June to September (JJAS), corresponding to the rainy season. On Central Sahel region (Figure 4(a)), BATS and CLM4.5 reproduce the annual cycle of air temperature with peaks in May $\left(39^{\circ} \mathrm{C}, 44^{\circ} \mathrm{C}\right.$, and $55^{\circ} \mathrm{C}$ respectively for $\mathrm{CPC}$, BATS and CLM); in August $\left(31^{\circ} \mathrm{C}, 31^{\circ} \mathrm{C}\right.$, and $47^{\circ} \mathrm{C}$ for CPC, BATS and CLM) and in October $\left(39^{\circ} \mathrm{C}, 44^{\circ} \mathrm{C}\right.$, and $55^{\circ} \mathrm{C}$ for CPC, BATS and CLM). The bias between the observations data and the CLM4.5 simulation, over the whole annual cycle, is constant (about $14^{\circ} \mathrm{C}$ ). The CLM4.5 and BATS experiments overestimate by $50 \%$ and $47 \%$ respectively of the maximum temperatures observed over this area. On West Sahel region, RegCM4 model overestimates the observational data (Figure 4 (b). There is a consistent bias $\left(10^{\circ} \mathrm{C}\right.$ or $\left.26 \%\right)$ between the CLM4.5 experiments and the $\mathrm{CPC}$ observations. The bias between BATS and observations is small $\left(5^{\circ} \mathrm{C}\right.$ or $\left.13 \%\right)$. However, BATS reproduces less well the maximum temperature peaks over the area (temporal shift of the peaks).

In the Guinea Coast area (Figure 4(c)), we note a fairly good results (BATS and CLM4.5) in terms of bias $\left(3^{\circ} \mathrm{C}\right.$ or $\left.8 \%\right)$. However, the temporal location of the simulated data is not correctly represented. The analysis of Figure 4(d) (West Africa area) shows a constant bias between CLM4.5 and the observations. CLM4.5 reproduces the surface temperature cycle with the correct temporal peaks but with notable bias of the order of $13^{\circ} \mathrm{C}(40 \%)$. This is reversed, in the BATS experiment, while the bias are minimized $\left(-2^{\circ} \mathrm{C}\right.$, or $\left.7 \%\right)$, the experiment reproduces less well the temporal peaks of temperature over the area (peaks in August shifted to September). 

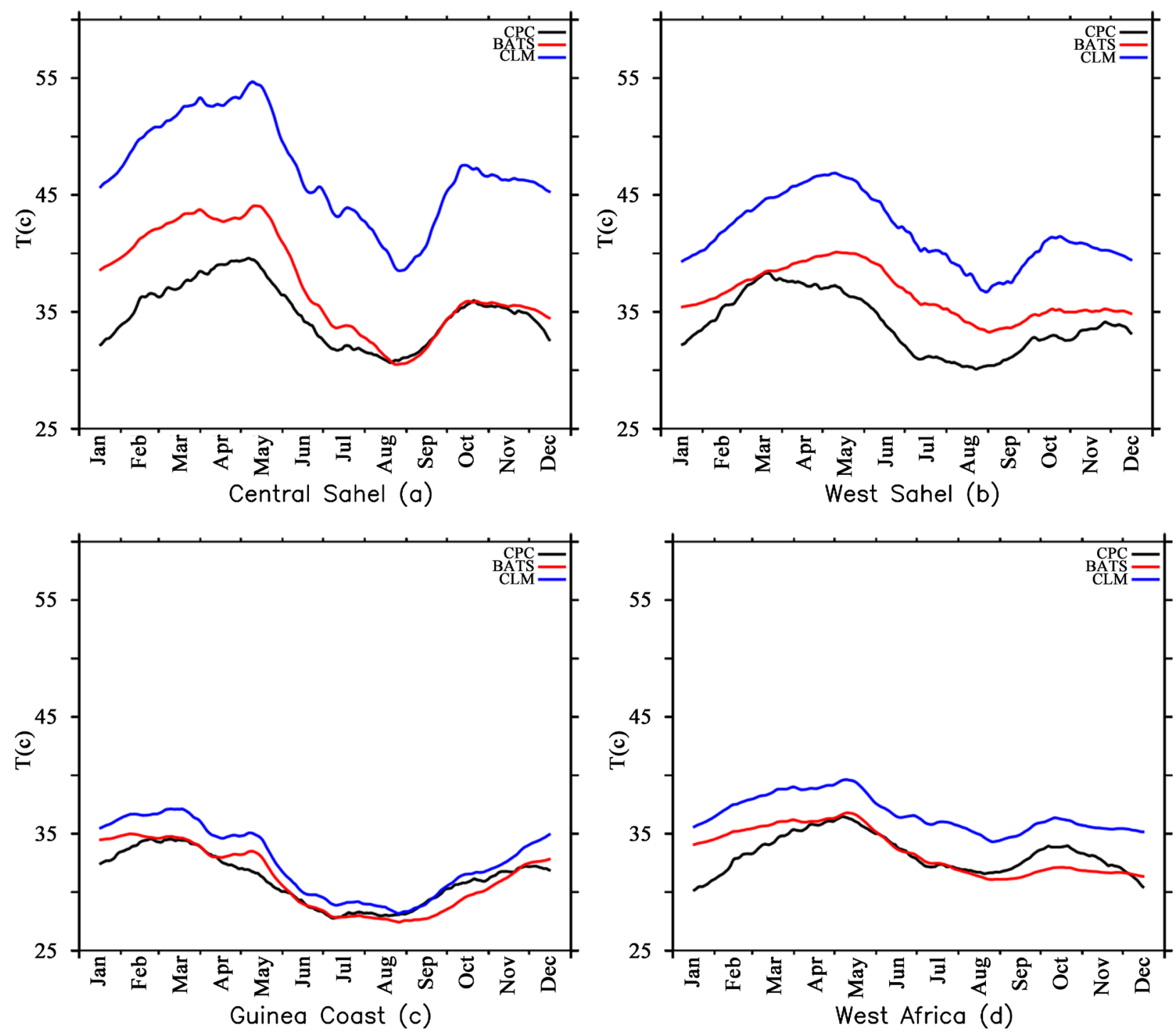

Figure 4. Annual cycle of surface temperature for simulated and observed data over different regions of West Africa.

\subsubsection{Statistical Analysis}

In order to analyze the performance of each surface scheme, a statistical study of the simulated and observed fields is carried out in this section. It will concern both the geographical location (grid point) and climatic parameter values (temperature or precipitation). After bringing the data (observations and simulations) to the same spatial resolution, we determine the biases, root mean square deviations (RMSE) and correlations at each grid point, over the period (20032007). Table 3: summarizes the statistical data related to the air temperature for the BATS and CLM experiments over the West African sub-regions. On the Central Sahel, the BATS show a fairly low root mean square deviation (RMSE), and remains poorly correlated with the observations (0.39). On the other hand, the CLM4.5 experiment shows a fairly significant correlation of 0.64 with RMSE three times those of BATS. This means that compared to BATS, CLM4.5 simulates better air temperatures of this area, while overestimating the observations (CPC). 
The West Sahel simulations are fairly well correlated with each other and have the same correlation (0.79) compared to the observational data. The RMSE values presented by the CLM4.5 experiment are two time more than BATS. On Guinea Coast, the two experiments have insignificant correlations 0.32 and 0.30 respectively for BATS and CLM4.5, while RMSE values are quite low. BATS still performs relatively well compared to CLM4.5 over the Guinea Coast. Over the entire West African domain, the simulations are fairly well correlated with each other (0.90) and almost the same correlation of 0.74 with the observational data. The RMSE values presented by the CLM4.5 experiment are two time than BATS, which suggests that compared to CLM, BATS still more efficient on this region.

\subsection{Precipitation}

\subsubsection{Monthly Variation}

Monthly average variations of daily precipitation from observed and simulated data, for the period 2003-2007 are shown in Figure 5. The simulated and observed data show similar patterns, reaching peaks at the same times. We note, however, that the RegCM4 model, underestimates in both simulations, precipitation over

Table 3. Root mean square difference (RMSE) and correlation (COR) for JJAS air temperature for simulations (BATS and CLM) and observations (CPC) over West Africa sub regions for 2004-2008 period.

\begin{tabular}{ccccccccccc}
\hline & \multicolumn{8}{c}{ Regions } \\
\cline { 2 - 10 } Temperature & \multicolumn{2}{c}{ WAF } & \multicolumn{2}{c}{ GCO } & \multicolumn{2}{c}{ WSA } & \multicolumn{2}{c}{ CSA } \\
\cline { 2 - 10 } & RMSE & COR & RMSE & COR & RMSE & COR & RMSE & COR \\
\hline BATS-CPC & 6.8 & 0.74 & 3.15 & 0.32 & 7.95 & 0.75 & 4.62 & 0.38 \\
CLM-CPC & 11.95 & 0.78 & 5.43 & 0.27 & 14.58 & 0.77 & 11.67 & 0.64 \\
CLM-BATS & 6.50 & 0.89 & 3.51 & 0.57 & 6.39 & 0.95 & 10.42 & 0.66 \\
\hline
\end{tabular}

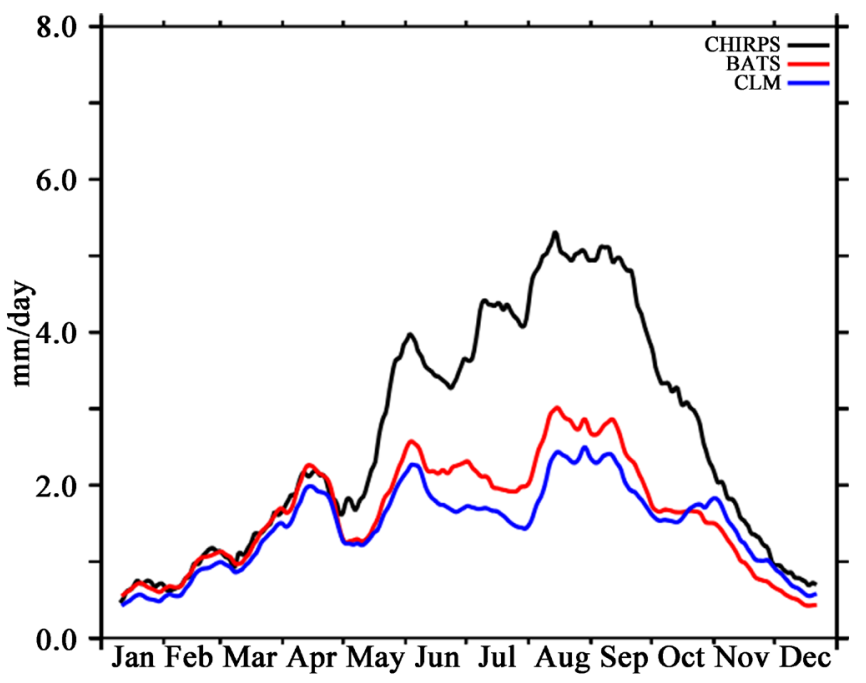

Figure 5. Monthly mean rainfall variation over West Africa, for CHIRPS and simulated data (BATS and CLM4.5 experiments). 
the entire domain. The average deviations are of the order of $1.5 \mathrm{~mm} \cdot \mathrm{day}^{-1}$. Biases between BATS and CLM experiences are significant during the months of June to September (JJAS), corresponding to the wet period over West Africa. The precipitation resulting from CLM4.5 is lower than that of BATS by about $0.5 \mathrm{~mm} \cdot \mathrm{day}^{-1}$.

\subsubsection{Spatial Distribution}

The spatial distribution of daily precipitation in JJAS (2003-2007) over West Africa is shown in Figure 6. Compared to observations, the maximum values of precipitation are located at orographic zones such as the Fouta Djalon $\left(16 \mathrm{~mm} \cdot\right.$ day $\left.^{-1}\right)$, the Joss plateau between Nigeria and Cameroon $\left(14 \mathrm{~mm} \cdot \mathrm{day}^{-1}\right.$.) Over the region from $0^{\circ} \mathrm{N}$ to $14^{\circ} \mathrm{N}$, precipitations varie from $4 \mathrm{~mm} \cdot$ day $^{-1}$ to $14 \mathrm{~mm} \cdot$ day $^{-1}$. The RegCM4 model simulates precipitation peaks in the orographic areas of Fouta Djalon, the West Atlantic coast and the Jos plateau (Nigeria-Cameroon border).
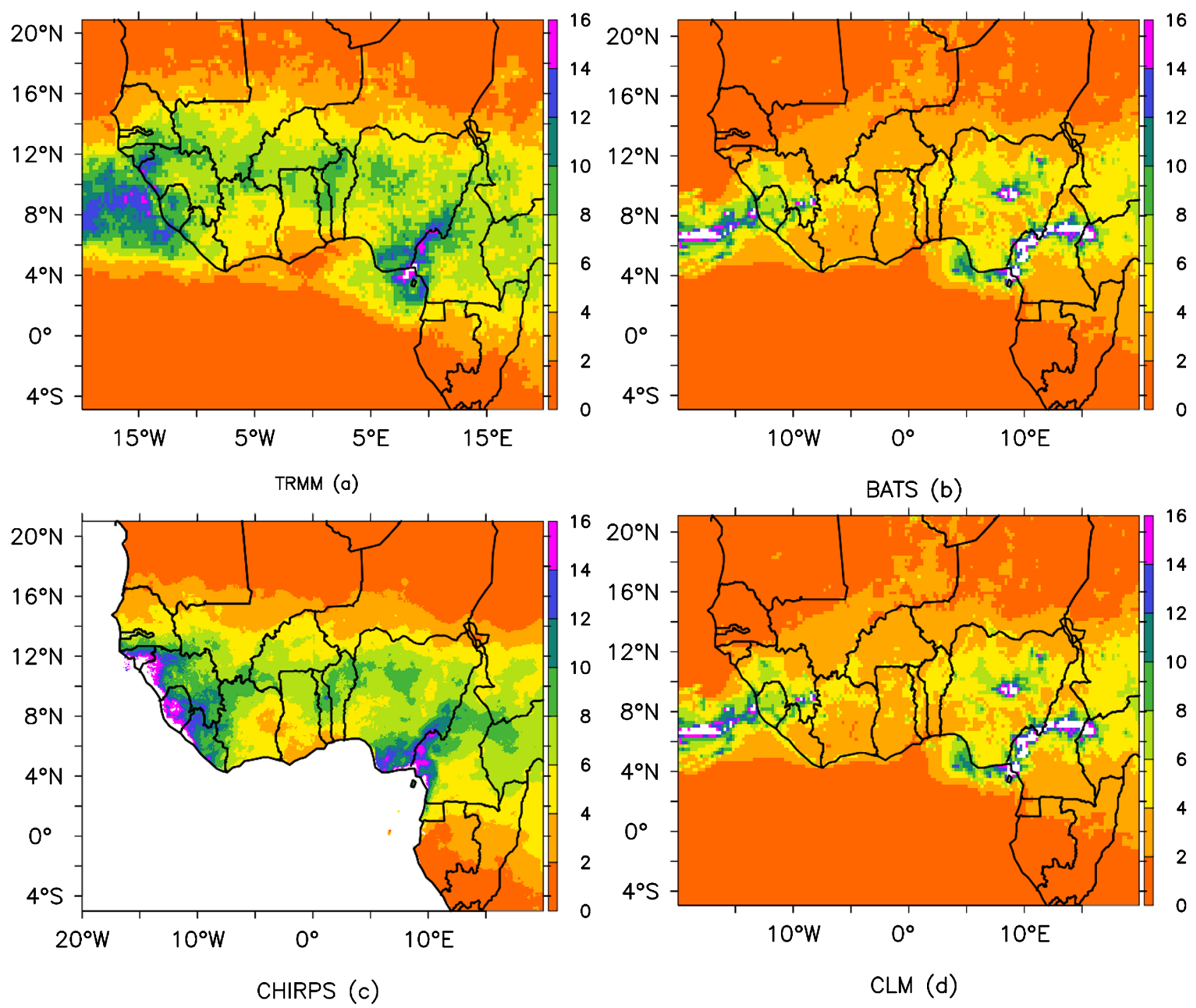

Figure 6. Spatial distribution of JJAS rainfall averaged over West Africa during 2003-2008, for RegCM simulations (BATS and CLM) and observations (TRMM and CHIRPS). 

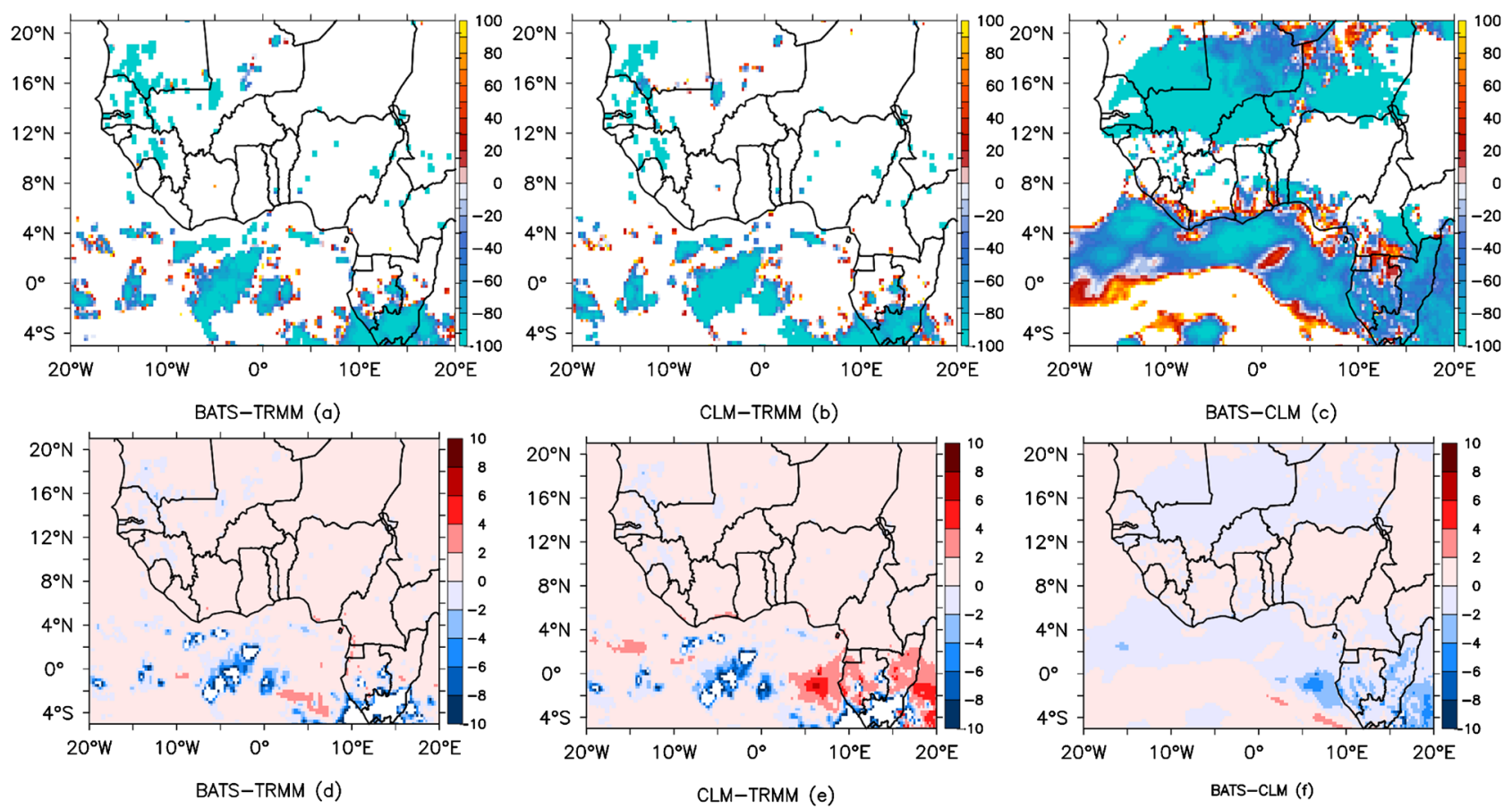

Figure 7. Bias of simulated and observed precipitation fields (BATS, CLM and TRMM) expressed in relative error (a)-(c) and in $\mathrm{mm} \cdot \mathrm{day}^{-1}$.

However, BATS and CLM4.5 experiments underestimated the daily precipitation peaks. Figure 7 shows the biases between different databases for precipitation fields. Biases are expressed in terms of relative error in percent (Figures $7(a)-(c)$ ) and in terms of mm.day ${ }^{-1}$ (Figures $7(d)-(f)$ ). BATS-TRMM, represents the relative error of daily precipitation at each grid point of the BATS experiment compared to TRMM observational data. The same applies to BATS-CLM which are the relative error between simulated.

The model, through BATS and CLM experiments, underestimates precipitation, mainly over the Atlantic with relative errors of $40 \%-60 \%$ (Figure 7 (a) and Figure 7(b)). In terms of daily precipitation, underestimation occures with negative biases of 2 to $6 \mathrm{~mm} \cdot \mathrm{day}^{-1}$, (Figure 7(d) and Figure 7(e)). Over the continent, the model underestimates precipitation mainly over two areas. The equatorial forest region of Congo on the one hand, and Mauritania and Senegal on the other, with relative errors of more than 60\% (Figure 7(a) and Figure 7(b)). Except these areas, BATS and CLM experiments produce fairly realistic precipitation fields with errors of less than $20 \%$ or biases of less than $2 \mathrm{~mm} \cdot \mathrm{day}^{-1}$. Comparing the simulations experiments each other, analysis shows an underestimation of the precipitation of the BATS experiment compared to the CLM experiment over the Atlantic. Otherwise CLM improves the precipitation over the ocean, Figure 7(c).

\subsubsection{Annual Mean Cycle}

The annual precipitation cycle for the sub regions are presented in Figure 8. The analysis of Central Sahel zone (Figure 8(a)) indicates that simulated precipitation 

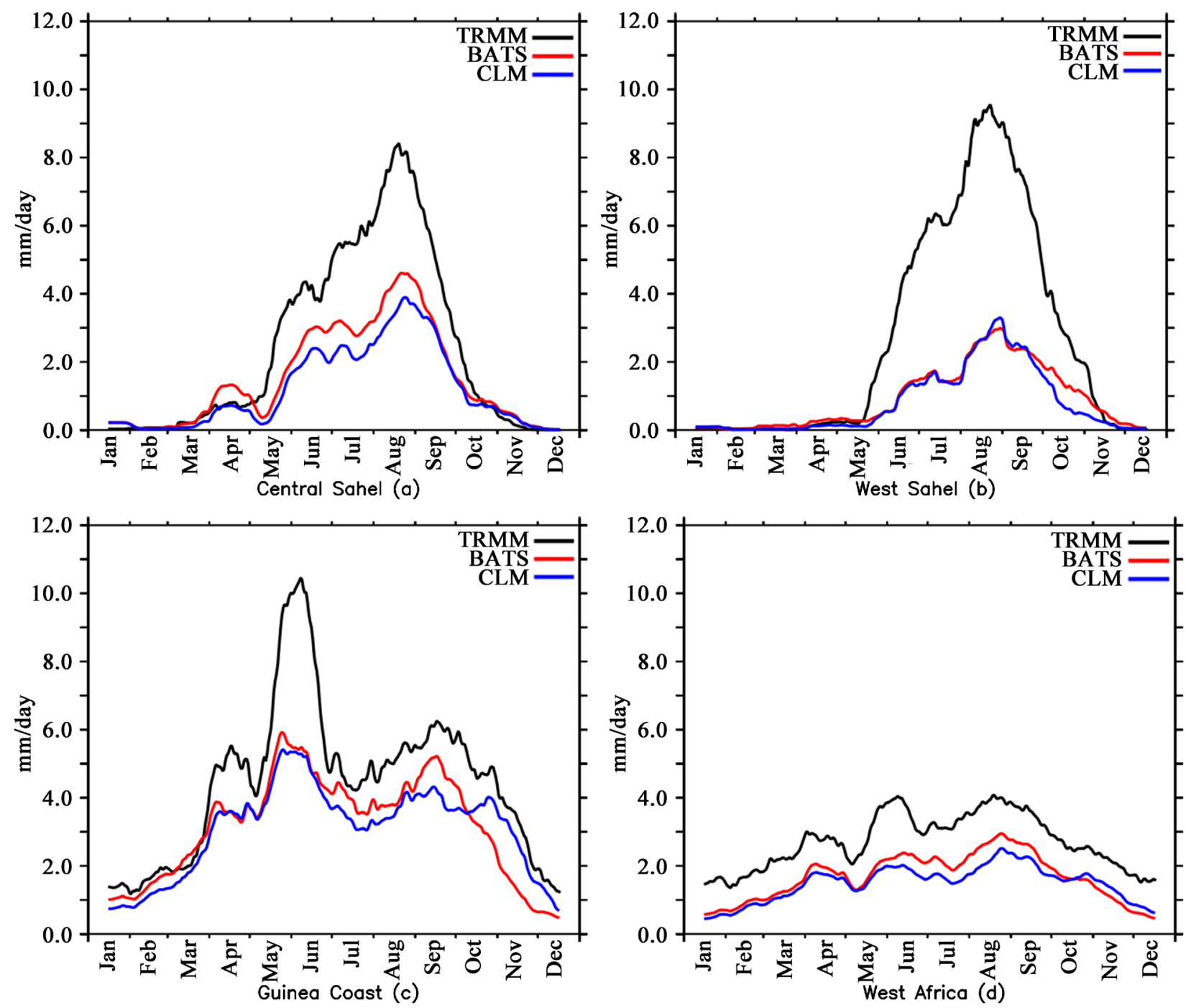

Figure 8. Annual rainfall cycle over different regions in West Africa. (a) Central Sahel, (b) West Sahel, (c) Guinea Cost and (d) West Africa.

are underestimated $\left(4 \mathrm{~mm} \cdot \mathrm{day}^{-1}\right)$, against $\left(8 \mathrm{~mm} \cdot \mathrm{day}^{-1}\right)$ for the observations. The biases with observations increase from the beginning of the season towards the peak in August corresponding to the period where the ZCIT reaches its most northerly position, the entire domain is then wet. After August month's the biases decrease. The discrepancies increase during the wet period due to the inability of the two surface schemes to represent precipitation during rainy season. Furthermore, in the Central Sahelian zone, 70\% of the precipitation is not due to local and convective phenomena, but to large-scale, non-convective precipitation [13]. The amplification of the biases in JJAS could not be attributed to the surface or convective scheme. However, the surface scheme BATS seems to better reproduce the observational data compared to CLM, the biases are smaller $20 \%$ for BATS and 50\% for CLM. The analysis of West Sahel zone (Figure 8(b)), shows significant biases between observations (peaks at $9 \mathrm{~mm} \cdot$ day $^{-1}$ ) and simulations (peaks at $3 \mathrm{~mm} \cdot \mathrm{day}^{-1}$ ). The model underestimates the daily precipitation 
amounts three times less than the observations. Here significant biases are limited to the JJAS rainy season; elsewhere in the area the simulated data (BATS and CLM) show the same pattern. The model underestimates with a significant deviation while the BATS and CLM experiments are almost similar over this area; this suggests that the two surface models are limited in their representation, especially during rainy season. The idea would be to analyze the convective and large-scale precipitation observed and simulated in order to determine the type of precipitation to which the biases are linked, (convective or large-scale precipitation type). Unfortunately we were limited in this study, by the availability of observational data.

The analysis of Guinea Coast area (Figure 8(c)) indicates that the bimodal character of the precipitation in this area is fairly well captured by the RegCM's model with peaks in June and October. The deviations due to the underestimation of the model are noticeable around the peaks, in June $\left(4 \mathrm{~mm} \cdot \mathrm{day}^{-1}\right)$ and October $\left(1 \mathrm{~mm} \cdot \mathrm{day}^{-1}\right)$ respectively for rainy season. Except these peaks, the BATS and CLM simulation experiments otherwise coincide fairly with each other and with the observations (less than $1 \mathrm{~mm} \cdot \mathrm{day}^{-1}$ ). The biases are minimized ( 1 $\mathrm{mm} \cdot \mathrm{day}^{-1)}$, compared to $4 \mathrm{~mm} \cdot \mathrm{day}^{-1}$ and $3 \mathrm{~mm} \cdot \mathrm{day}^{-1}$ respectively in the Central Sahel and West Sahel zones. The Guinea Coast is an area close to the coast of the Gulf of Guinea, where humidity is frequently adverted. The marine humidity and vegetation density conducive to the development of local climatic phenomena, which are fairly well taken into account by the formulation of the surface patterns [2].

Analysis of the entire West Africa domain indicates that the CLM4.5 and BATS remain fairly close, the biases are less than $1 \mathrm{~mm} \cdot \mathrm{day}^{-1}$, and moreover the simulated data sometimes coincides with the observations. The model underestimates the daily precipitation, over the area with mean bias of $2 \mathrm{~mm} \cdot \mathrm{day}^{-1}$.

\subsubsection{Statistical Analysis}

Table 4 shows the correlation coefficients and root mean square deviations of JJAS precipitation for the simulated and observed data. On the Central Sahel BATS has a root mean square deviation (RMSE) of 11.13 compared to 11.10 for CLM4.5 and a non-significant correlation about 0.3 , the RMSE of the two experiments are of the

Table 4. Root mean square difference and correlation for JJAS Precipitation for simulations (BATS and CLM) and observations (TRMM) over West Africa sub regions for 2004-2008 period.

\begin{tabular}{cccccccccc}
\hline & \multicolumn{8}{c}{ Regions } \\
\cline { 2 - 9 } Precipitation & \multicolumn{2}{c}{ WAF } & \multicolumn{2}{c}{ GCO } & \multicolumn{2}{c}{ WSA } & \multicolumn{2}{c}{ CSA } \\
\cline { 2 - 10 } & RMSE & COR & RMSE & COR & RMSE & COR & RMSE & COR \\
\hline BATS-TRMM & 11.52 & 0.46 & 14.88 & 0.38 & 11.95 & 0.44 & 11.13 & 0.30 \\
CLM-TRMM & 10.50 & 0.58 & 12.68 & 0.50 & 11.91 & 0.40 & 11.10 & 0.28 \\
CLM-BATS & 7.60 & 0.62 & 9.08 & 0.68 & 2.56 & 0.82 & 3.31 & 0.61 \\
\hline
\end{tabular}


same order. In this region, the two surface schemes perform poorly in the restitution of the observations. Concerning the West Sahel region, the simulations have about the same RMSE (11.95), the correlation is 0.44 for BATS against 0.40 for the CLM4.5 experiment. The two experiments are highly correlated (0.82), but the correlations between simulations and observation fields remain low (0.4). In the Guinea Coast region the BATS and CLM present correlation of 0.38 and 0.50 with observations, respectively. These correlation values are quite close to those of the West Sahel area. Over the whole West Africa domain, the BATS simulations present a correlation of 0.46 , against 0.58 for CLM4.5, with RSME of 11.52 and 10.4 for BATS and CLM respectively. The performance of the RegCM's model, involving the BATS and CLM surface schemes, is mixed and varies from one area to another and from one scheme to another. The most significant correlations between simulated and observed precipitation fields are ranged from 0.40 to 0.58 . The inter-correlation between simulated data is more marked, varying from 0.4 to 0.7 . The two simulation experiments underestimate precipitation over West Africa, especially.

\subsubsection{Taylor Diagram}

The Taylor diagram, Figure 9, allow a combined synthesized view of the pattern correlation coefficient and the JJAS standard deviation of precipitation from the different sensitivity studies with respect to TRMM over West Africa sub regions. For the entire West African domain, CLM and BATS configurations have almost the save performance with values of normalized standard deviation much closer to 0.65 . However, CLM experience presents a better spatial correlation, 0.4 compared to BATS. The difference in performance between the two experiments on West African region is not enough significant. Over the Guinea coast sub region, BATS present better values of normalized standard deviation. However, regarding the spatial correlation, value about 0.5 as in the CLM experience is better. For central Sahel, CLM and BATS show the same pattern, and reproduce weakly the observations on this sub region, normalized standard deviation and spatial correlation are closer to 1.2 and 0.3 respectively. For west Sahel, CLM show better pattern compared to BATS, spatial correlation are respectively closer to 0.4 and 0.2 . However, both experiments reproduce the TRMM observations rather weakly. Following the analysis based on the Taylor diagram, we deduce that the BATS and CLM experiences perform close to each other across West Africa and the sub-regions. However, both experiments show low standard deviations and spatial correlations compared to TRMM observations, and finally the performance of the RegCM's model is lower in Sahelian zones.

\subsubsection{BATS and CLM4.5 Performances}

A comparative analysis of simulations (BATS, CLM4.5) and observed data on precipitation (TRMM and CHIRPS) and temperature (CPC) was carried out. The results show a fairly realistic restitution of West Africa's climatology. The analysis indicates correlations of 0.60 to 0.82 between the simulated fields (BATS 

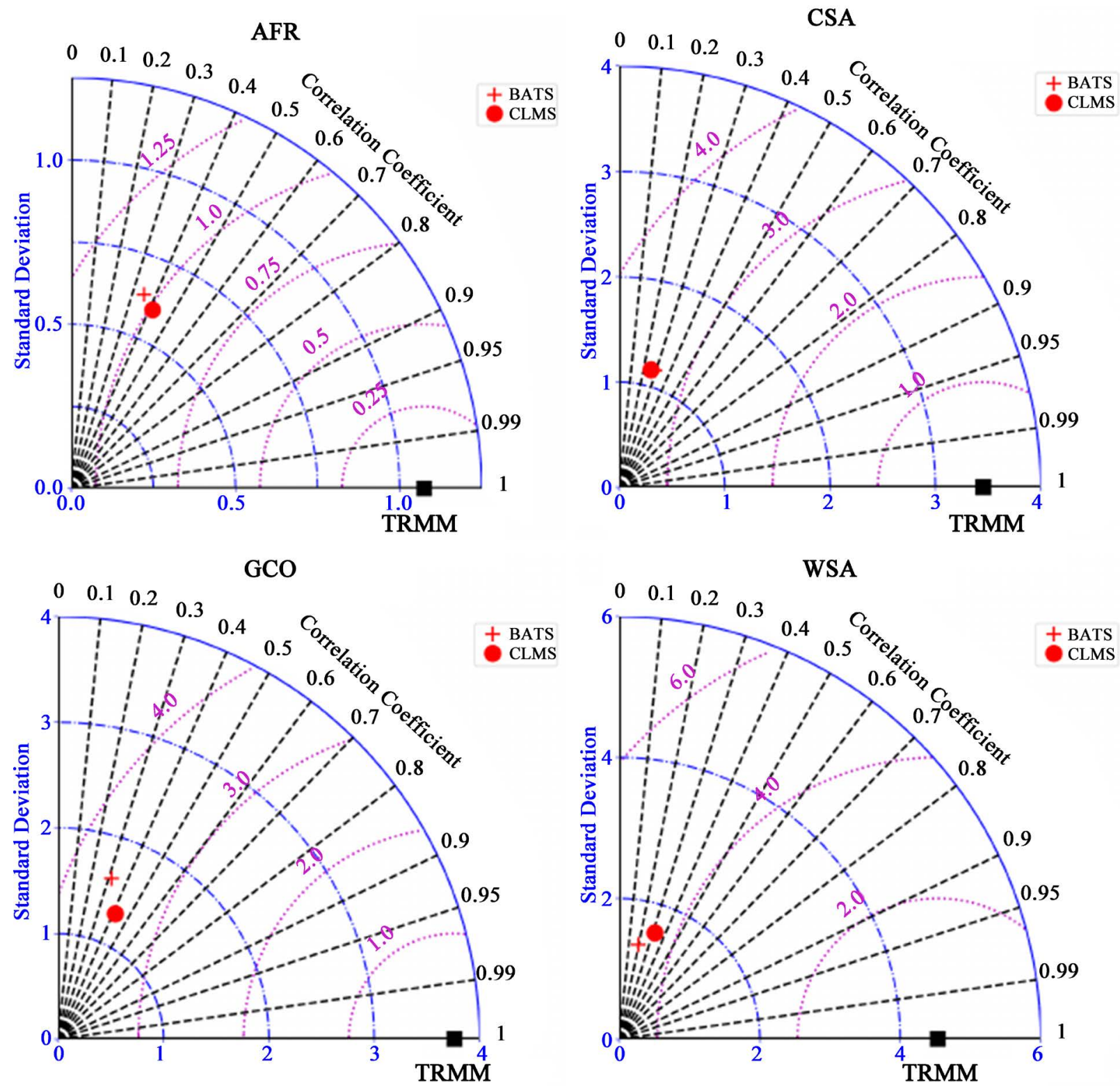

Figure 9. Taylor diagram summarizes model performance for JJAS precipitation over West Africa (AFR), Central Sahel (CSA), West Sahel (WSA) and Guinea coast (GCO).

and CLM4.5) for precipitation. For air temperatures, the correlations range from 0.57 to 0.95 . Overall the results of the study suggest a mixed performance of the BATS and CLM4.5 surface schemes over West Africa for the RegCM4 model. The temporal localization (seasonal effect), spatial distribution (grid points) and magnitude of climate parameters (bias) are not simultaneously improved. Despite a fairly detailed and elaborate formulation of the CLM4.5 surface scheme, the performance of the two schemes over West Africa remains mixed. Indeed, they vary from one area to another and are equal in some region (e.g. WSA). Similar results were also reported by Chung et al. [8] and Wang et al. [32], respectively in comparative studies of RegCM's surface schemes over South-East Asia and the Tibetan Plateau. Their work revealed that replacing the BATS sur- 
face scheme with the CLM4.5 surface scheme in the model configuration does not systematically induce an improvement in RegCM's model performance.

\section{Conclusions and Perspectives}

In order to improve the simulations of the regional climate model RegCM4 over West Africa, two experiments were carried out from January 2003 to December 2007, with BATS and CLM4.5 land surface schemes. The simulated data were compared with observational data from CHIRPS and TRMM for precipitation and CPC for air temperature. Both BATS and CLM4.5 experimental results reproduce the seasonal precipitation cycles, spatial distribution and cumulative precipitation quite well. The spatial correlation coefficients between model output (CLM4.5, BATS) and observational data are quite significant from one season to the other. Concerning air temperature, the simulations reproduce fairly well the zonal character of temperatures over West Africa, the location of cold areas (orographic zones, coasts of the Gulf of Guinea and forest zones) and hot regions (Sahara).

The RegCM4 model reproduces the general pattern of precipitation and temperature climatology over the area of interest. While the CLM4.5 experiment restores the seasonal cycles and spatial distribution, biases of Precipitation and temperature increase by $20 \%$ and $50 \%$ respectively. Precipitation is underestimated; especially in the wet season JJAS by values ranging from $4 \mathrm{~mm} \cdot$ day $^{-1}$ to $14 \mathrm{~mm} \cdot$ day $^{-1}$. CLM4.5 introduces an improvement in the seasonal cycle and spatial distribution of air temperatures. However, the positive biases already existing with BATS are amplified particularly over the West Sahel and Central Sahel areas. CLM4.5, fails to minimize the overestimates of air temperature especially in the Sahel and Sahara regions.

Statistical analysis of observed and simulated field show: 1) for the BATS experiment, the correlations range from 0.27 to 0.46 and 0.32 to 0.75 for precipitation and air temperatures, respectively; 2) for the CLM4.5 experiment, the correlations range from 0.25 to 0.58 and 0.26 to 0.77 for precipitation and air temperatures, respectively. Analysis between BATS and CLM model outputs also indicates, correlations ranging from 0.60 to 0.82 , and from 0.57 to 0.95 for precipitation, and $2 \mathrm{~m}$ air temperature respectively.

This study suggests the use of a combined performance of the BATS and CLM4.5 surface schemes over West Africa for the RegCM4 model. For future studies, it is, therefore, necessary to extend the analysis to a) other climate parameters such as (precipitation types, surface turbulent flow etc); b) atmospheric circulation, monsoon flow, JET and JEA and c) a variety of observational data, at least three different datasets.

\section{Acknowledgements}

We thank the Université Félix Houphouët-Boigny, Abidjan, the Laboratory of Matter Sciences, Environment and Solar Energy (LASMES) that allowed us to 
complete this work. We also thank the Computing Center of the Bingerville scientific pole which provided the regional model RegCM, hosted us for part of this work and provided the equipment to simulate the climate of West Africa. Thanks to Arona DIEDHIOU for his frequent help.

\section{Conflicts of Interest}

The authors declare no conflicts of interest regarding the publication of this paper.

\section{References}

[1] Rummukainen, M. (2010) State-of-the-Art with Regional Climate Models. WIREs Climate Change, 1, 82-96. https://doi.org/10.1002/wcc.8

[2] Giorgi, F., Coppola, E., Solmon, F., Mariotti, L., Sylla, M.B., Bi, X., et al. (2012) RegCM4: Model Description and Preliminary Tests over Multiple CORDEX Domains. Climate Research, 52, 7-29. https://doi.org/10.3354/cr01018

[3] Sylla, M.B., Giorgi, F., Coppola, E. and Mariotti, L. (2013) Uncertainties in Daily Rainfall over Africa: Assessment of Gridded Observation Products and Evaluation of a Regional Climate Model Simulation. International Journal of Climatology, 33, 1805-1817. https://doi.org/10.1002/joc.3551

[4] Martínez-Castro, D., Porfirio da Rocha, R., Bezanilla-Morlot, A., Alvarez-Escudero, L., Reyes-Fernández, J.P., Silva-Vidal, Y., et al. (2006) Sensitivity Studies of the RegCM3 Simulation of Summer Precipitation, Temperature and Local Wind Field in the Caribbean Region. Theoretical and Applied Climatology, 86, 5-22. https://doi.org/10.1007/s00704-005-0201-9

[5] Sylla, M.B., Gaye, A.T., Pal, J.S., Jenkins, G.S. and Bi, X.Q. (2009) High-Resolution Simulations of West African Climate Using Regional Climate Model (RegCM3) with Different Lateral Boundary Conditions. Theoretical and Applied Climatology, 98, 293-314. https://doi.org/10.1007/s00704-009-0110-4

[6] Diallo, I., Sylla, M.B., Camara, M. and Gaye, A.T. (2013) Interannual Variability of Rainfall over the Sahel Based on Multiple Regional Climate Models Simulations. Theoretical and Applied Climatology, 113, 351-362. https://doi.org/10.1007/s00704-012-0791-y

[7] Raju, P.V.S., Bhatla, R., Almazroui, M. and Assiri, M. (2015) Performance of Convection Schemes on the Simulation of Summer Monsoon Features over the South Asia CORDEX Domain Using RegCM-4.3. International Journal of Climatology, 35, 4695-4706. https://doi.org/10.1002/joc.4317

[8] Chung, J.X., Juneng, L., Tangang, F. and Jamaluddin, A.F. (2018) Performances of BATS and CLM Land-Surface Schemes in RegCM4 in Simulating Precipitation over CORDEX Southeast Asia Domain. International Journal of Climatology, 38, 794-810. https://doi.org/10.1002/joc.5211

[9] Koné, B., Diedhiou, A., Sylla, M.B., Giorgi, F., Anquetin, S., Bamba, A., et al. (2018) Sensitivity Study of the Regional Climate Model RegCM4 to Different Convective Schemes over West Africa. Earth System Dynamics, 9, 1261-1278. https://doi.org/10.5194/esd-9-1261-2018

[10] Chen, L., Ma, Z. and Fan, X. (2012) A Comparative Study of Two Land Surface Schemes in WRF Model over Eastern China. Journal of Tropical Meteorology, 18, 445-456.

[11] Steiner, A.L., Pal, J.S., Rauscher, S.A., Bell, J.L., Diffenbaugh, N.S., Boone, A., et al. 
(2009) Land Surface Coupling in Regional Climate Simulations of the West African Monsoon. Climate Dynamics, 33, 869-892.

https://doi.org/10.1007/s00382-009-0543-6

[12] Halder, S., Saha, S., Dirmeyer, P., Chase, T. and Goswami, B.N. (2016) Investigating the Impact of Land-Use Land-Cover Change on Indian Summer Monsoon Daily Rainfall and Temperature during 1951-2005 Using a Regional Climate Model. $H y$ drology and Earth System Sciences, 20, 1765-1784.

https://doi.org/10.5194/hess-20-1765-2016

[13] Wang, X., Yang, M. and Pang, G. (2015) Influences of Two Land-Surface Schemes on RegCM4 Precipitation Simulations over the Tibetan Plateau. Advances in Meteorolgy, 2015, Article ID: 106891. https://doi.org/10.1155/2015/106891

[14] Grell, G.A., Dudhia, J. and Stauffer, D.R. (1994) A Description of the Fifth-Generation Penn State/NCAR Mesoscale Model (MM5) (No. NCAR/TN-398+STR). University Corporation for Atmospheric Research, Boulder.

[15] Kiehl, J.T., Hack, J.J., Bonan, G.B., Boville, B.A. and Briegleb, B.P. (1996) Description of the NCAR Community Climate Model (CCM3). Technical Note, National Center for Atmospheric Research, Boulder.

[16] Zakey, A.S., Solmon, F. and Giorgi, F. (2006) Implementation and Testing of a Desert Dust Module in a Regional Climate Model. Atmospheric Chemistry and Physics, 6, 4687-4704. https://doi.org/10.5194/acp-6-4687-2006

[17] Dickinson, R., Henderson-Sellers, A. and Kennedy, P. (1993) Biosphere-Atmosphere Transfer Scheme (BATS) Version 1e as Coupled to the NCAR Community Climate Model. UCAR (University Corporation for Atmospheric Research)/NCAR (National Center for Atmospheric Research), Boulder.

[18] Wilson, M.F. (1984) The Construction and Use of Land Surface Information in a General Circulation Climate Model. PhD Thesis, University of Liverpool, Liverpool, $234 \mathrm{p}$.

[19] Giorgi, F., Francisco, R. and Pal, J. (2003) Effects of a Subgrid-Scale Topography and Land Use Scheme on the Simulation of Surface Climate and Hydrology. Part I: Effects of Temperature and Water Vapor Disaggregation. Journal of Hydrometeorology, 4, 317-333. https://doi.org/10.1175/1525-7541(2003)4<317:EOASTA>2.0.CO;2

[20] Oleson, K.W., Niu, G.-Y., Yang, Z.-L., Lawrence, D.M., Thornton, P.E., Lawrence, P.J., et al. (2008) Improvements to the Community Land Model and Their Impact on the Hydrological Cycle. Journal of Geophysical Research: Biogeosciences, 113, Article ID: G01021. https://doi.org/10.1029/2007JG000563

[21] Bonan, G.B., Levis, S., Kergoat, L. and Oleson, K.W. (2002) Landscapes as Patches of Plant Functional Types: An Integrating Concept for Climate and Ecosystem Models. Global Biogeochemical Cycles, 16, 5-1-5-23.

https://doi.org/10.1029/2000GB001360

[22] Lawrence, P.J. and Chase, T.N. (2007) Representing a New Modis Consistent Land Surface in the Community Land Model (CLM 3.0). Journal of Geophysical Research: Biogeosciences, 112, Article ID: G01023.

https://doi.org/10.1029/2006JG000168

[23] Thornton, P.E. and Zimmermann, N.E. (2007) An Improved Canopy Integration Scheme for a Land Surface Model with Prognostic Canopy Structure. Journal of Climate, 20, 3902-3923. https://doi.org/10.1175/JCLI4222.1

[24] Dee, D.P., Uppala, S.M., Simmons, A.J., Berrisford, P., Poli, P., Kobayashi, S., et al. (2011) The ERA-Interim Reanalysis: Configuration and Performance of the Data 
Assimilation System. Quarterly Journal of the Royal Meteorological Society, 137, 553-597. https://doi.org/10.1002/qj.828

[25] Huffman, G.J., Bolvin, D.T., Nelkin, E.J., Wolff, D.B., Adler, R.F., Gu, G., et al. (2007) The TRMM Multisatellite Precipitation Analysis (TMPA): Quasi-Global, Multiyear, Combined-Sensor Precipitation Estimates at Fine Scales. Journal of $\mathrm{Hy}$ drometeorology, 8, 38-55. https://doi.org/10.1175/JHM560.1

[26] Funk, C., Peterson, P., Landsfeld, M., Pedreros, D., Verdin, J., Shukla, S., et al. (2015) The Climate Hazards Infrared Precipitation with Stations-A New Environmental Record for Monitoring Extremes. Scientific Data, 2, Article No. 150066. https://doi.org/10.1038/sdata.2015.66

[27] Xie, P. and Arkin, P.A. (1997) Global Precipitation: A 17-Year Monthly Analysis Based on Gauge Observations, Satellite Estimates, and Numerical Model Outputs. Bulletin of the American Meteorological Society, 78, 2539-2558. https://doi.org/10.1175/1520-0477(1997)078<2539:GPAYMA>2.0.CO;2

[28] Nikulin, G., Jones, C., Giorgi, F., Asrar, G., Büchner, M., Cerezo-Mota, R., et al. (2012) Precipitation Climatology in an Ensemble of CORDEX-Africa Regional Climate Simulations. Journal of Climate, 25, 6057-6078. https://doi.org/10.1175/JCLI-D-11-00375.1

[29] Taylor, K.E. (2001) Summarizing Multiple Aspects of Model Performance in a Single Diagram. Journal of Geophysical Research: Atmospheres, 106, 7183-7192. https://doi.org/10.1029/2000JD900719

[30] Cook, K.H. (1999) Generation of the African Easterly Jet and Its Role in Determining West African Precipitation. Journal of Climate, 12, 1165-1184. https://doi.org/10.1175/1520-0442(1999)012<1165:GOTAEJ>2.0.CO;2

[31] Sylla, M.B., Giorgi, F. and Stordal, F. (2012) Large-Scale Origins of Rainfall and Temperature Bias in High-Resolution Simulations over Southern Africa. Climate Research, 52, 193-211. https://doi.org/10.3354/cr01044

[32] Wang, W. and Seaman, N.L. (1997) A Comparison Study of Convective Parameterization Schemes in a Mesoscale Model. Monthly Weather Review, 125, 252-278. https://doi.org/10.1175/1520-0493(1997)125<0252:ACSOCP >2.0.CO;2 